(0) MICROBIAL CELL
000 FACTORIES
000 (0)

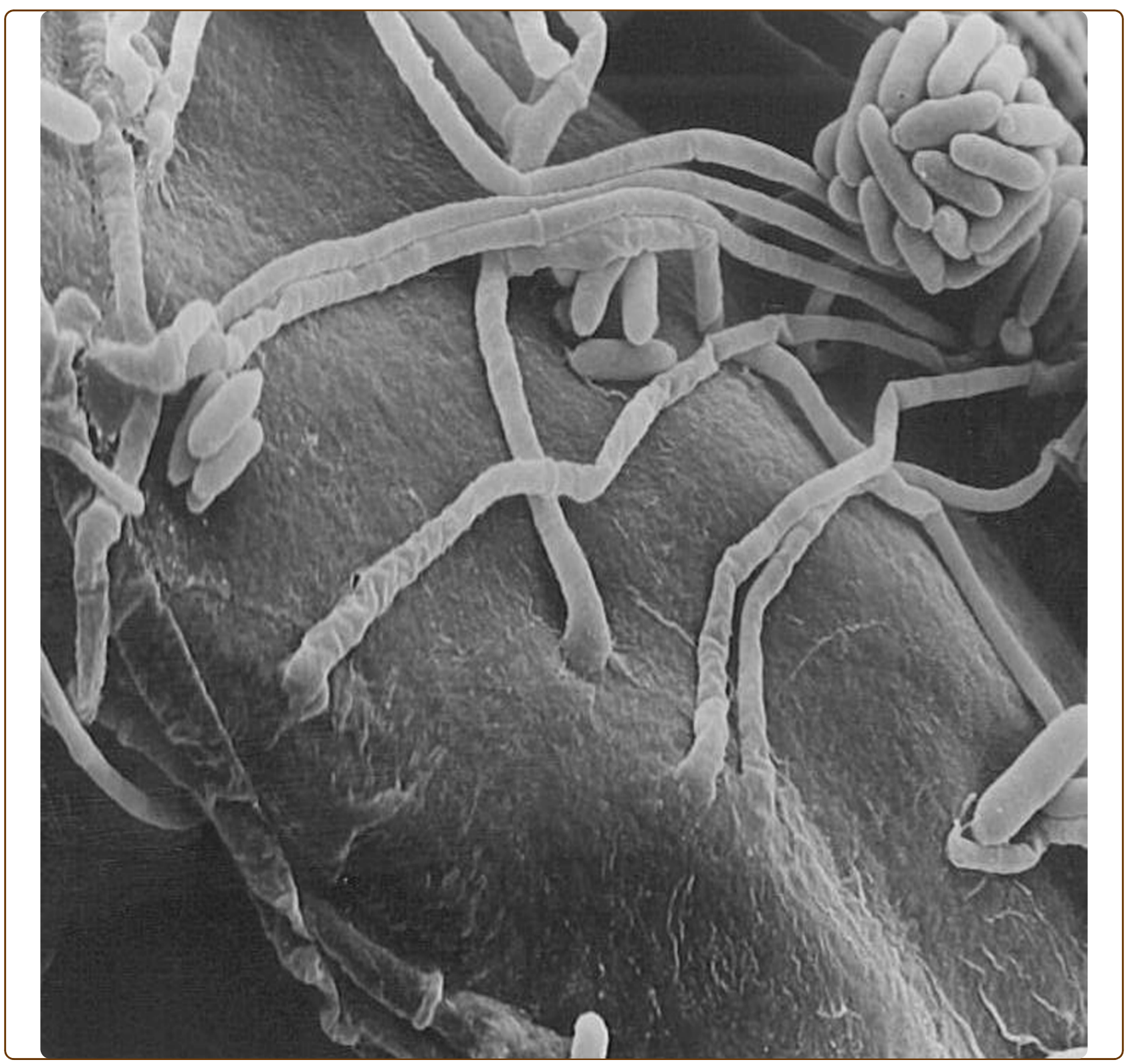

Combined effects of agitation and aeration on the chitinolytic enzymes production by the Antarctic fungus Lecanicillium muscarium CCFEE 5003

Fenice et al. 


\title{
Combined effects of agitation and aeration on the chitinolytic enzymes production by the Antarctic fungus Lecanicillium muscarium CCFEE 5003
}

\author{
Massimiliano Fenice*, Paolo Barghini, Laura Selbmann and Federico Federici
}

\begin{abstract}
Background: The Antarctic fungus Lecanicillium muscarium CCFEE 5003 is one of the most powerful chitinolytic organisms. It can produce high level of chitinolytic enzymes in a wide range of temperatures $\left(5-30^{\circ} \mathrm{C}\right)$. Chitinolytic enzymes have lot of applications but their industrial production is still rather limited and no cold-active enzymes are produced. In view of massive production of L. muscarium chitinolytic enzymes, its cultivation in bioreactors is mandatory. Microbial cultivation and/or their metabolite production in bioreactors are sometime not possible and must be verified and optimized for possible exploitation. Agitation and aeration are the most important parameters in order to allow process up-scaling to the industrial level.
\end{abstract}

Results: In this study, submerged cultures of L. muscarium CCFEE 5003 were carried out in a 2-L bench-top CSTR bioreactor in order to optimise the production of chitinolytic enzymes. The effect of stirrer speed (range 200-500 rpm) and aeration rate (range 0.5-1.5 vvm) combination was studied, by Response Surface Methodology (RSM), in a medium containing $1.0 \%$ yeast nitrogen base and $1 \%$ colloidal chitin. Optimization was carried out, within a "quadratic D-optimal" model, using quantitative and quantitative-multilevel factors for aeration and agitation, respectively. The model showed very good correlation parameters $\left(R^{2}, 0.931 ; Q^{2}, 0.869\right)$ and the maximum of activity $(373.0 \mathrm{U} / \mathrm{L})$ was predicted at ca. $327 \mathrm{rpm}$ and $1.1 \mathrm{vvm}$. However, the experimental data showed that highest activity $(383.7 \pm 7.8 \mathrm{U} / \mathrm{L})$ was recorded at $1 \mathrm{vvm}$ and $300 \mathrm{rpm}$. Evident shear effect caused by stirrer speed and, partially, by high aeration rates were observed. Under optimized conditions in bioreactor the fungus was able to produce a higher number of chitinolytic enzymes than those released in shaken flasks. In addition, production was $23 \%$ higher.

Conclusions: This work demonstrated the attitude of L. muscarium CCFEE 5003 to grow in bench-top bioreactor; outlined the strong influence of aeration and agitation on its growth and enzyme production and identified the optimal conditions for possible production at the industrial level.

Keywords: Chitinolytic enzymes production, Lecanicillium muscarium, Response Surface Methodology, Agitation and aeration

\section{Background}

Chitinolytic enzymes (generally called chitinases) have been widely studied and some produced by fungi are of great interest for possible applications. Traditionally, these hydrolases could be employed in chitin hydrolysis, production of chitin derivatives, protoplast formation and bio-control of pathogenic organisms [1-4]. Some

\footnotetext{
* Correspondence: fenice@unitus.it

Dipartimento di Scienze Ecologiche e Biologiche, Largo Università snc, University of Tuscia, I-01100, Viterbo, Italy
}

unconventional and very interesting applications in food and wine industries have been successfully tested at laboratory level $[5,6]$. In this context, the search of new chitinolytic organisms and/or enzymes is still full of interest. In addition, in some specific fields, chitinolytic cold tolerant microorganisms or enzymes could solve a number of practical problems.

The production of chitinases at industrial level is rather scarce and mainly obtained from Serratia marcescens and Streptomyces griseus; the only commercial 
chitinase preparation of fungal origin comes from selected strains of Trichoderma harzianum. However, the cost of these enzymes is still too high and large scale applications are still expensive and scarcely profitable. Already from their early works, Aloise et al. [7] proposed an industrial process to obtain $\mathrm{N}$-acetyl-D-glucosamine (NAG) using S. marcescens chitinolytic enzyme.

So far, however, no process, using fungi and/or their enzymes, has been studied in details in view of industrial scale-up.

In this context, setting of best bioprocess (fermentation) conditions is very important and, in particular, understanding the effect of agitation/aeration on microbial productions is generally recognized as a mandatory key step for the scale-up to the industrial level.

The Antarctic fungus Lecanicillium muscarium CCFEE 5003 , belonging to a species generally recognized as entomopathogenic, produces high levels of chitinases, when grown on raw or colloidal chitin, in a wide range $\left(5-30^{\circ} \mathrm{C}\right)$ of temperatures with an optimum at $25^{\circ} \mathrm{C}[8,9]$. The chitinolytic activity of this psychrotolerant organism, also related to its ability to attack and destroy other fungal organisms (mycoparasitism), is associated to the production of various enzymes including chitinases, glucanases and proteases [3,9]. Strain CCFEE 5003 is really very powerful at low temperature. It is even more efficient than T. harzianum that is commercialized as a bio-control mycoparasitic agent against plant pathogens but shows scarce activity at low temperature and in cold environments $[10,11]$

In view of potential applications of both the fungus and its chitinases, massive (industrial) optimized cultivation is necessary: this could only occur in bioreactors. However, since sometimes microorganism's growth in bioreactors is scarce and their release of metabolites fails, the capacity to growth and produce in such conditions must be proved [12].

It is worth noting that, nowadays, it is generally recognized that optimization of microbial production process should be performed using fast, efficient and correctly designed model-based methods [13]. Unfortunately, many recent publications show that scientists continue to employ techniques that permit to vary "one-variable-ata-time" (OVT), only. This does not consent to elucidate the combined effect of the various parameters and underline which factors could have significant interactions (synergy or antagonism). Moreover, it is not possible to understand which variables have real influence on the response (result) and to predict the effect exerted by the combined variation of the factors. This happens also for the optimization of fungal chitinases production. In fact, till now modeling has been used for process optimization in shaken flasks only, while in bioreactor optimization has been carried by the OVT technique [14-18]. In addition, most of the works regarded process optimization for Trichoderma species; the only paper available for the optimization of chitinolytic enzymes by $L$. muscarium is that of Liu et al. [15] that was carried out with traditional methods (OVT).

In this paper we studied by RSM the combined effects of agitation and aeration on the production of chitinolytic enzymes by $L$. muscarium CCFEE 5003, cultivated in a 2-1 bench-top CSTR bioreactor, in view of possible scale-up to the industrial level. In this context, effects of these parameters on the volumetric mass-transfer coefficient $\left(\mathrm{K}_{\mathrm{L}} \mathrm{a}\right)$ and time course of chitinolytic enzymes production and main bioprocess variables under optimized conditions are also reported.

\section{Results and discussion}

Experimental design is the investigation planning carried out in order to extract the maximum amount of information form the collected data by performing the minimum number of experiments. The idea is to vary all relevant factors simultaneously over a set of defined experiments and to connect the results by a mathematical model that is used for data interpretation, prediction and optimization. The evolution of statistical experimental designs, started with the very early works of Fisher in the twenties of last century and refined by others, provides the user with powerful methodologies for efficient experimentation [19-21].

RSM, one of the most efficient and performing methods for experimental design, is largely used in fermentation technology to optimize process parameters both at laboratory and industrial level [22,23]. However, for the optimization of fungal chitinases production, this method has been used only for experiments in shaken flasks $[14,18]$. As far as we know, this is the first paper dealing with the optimization of agitation and aeration in CSTR for the production of fungal chitinases by RSM. Moreover, this is the first work assessing the ability of $L$. muscarium to grow and produce high level of chitinolytic enzymes in stirred bioreactors.

\section{Model performance}

Data were best fitted by a polynomial quadratic equation, as it can be inferred by the good agreement of experimental data with those estimated by the model.

As indicated by the Anova table, the model revealed high reliability and good statistical performance (Table 1). For both the analysed responses, the probability for the regression was significant at $95 \%$ and there was no lack of fit.

As for the enzyme activity, the correlation coefficient $\left(R^{2}\right)$, indicating the fraction of response variation explained by the model, was high (0.931). This means 
Table 1 Statistical parameter measuring the correlation and significance of the model (Anova table)

\begin{tabular}{|c|c|c|c|c|c|c|}
\hline Enzyme activity & $\mathrm{DF}$ & SS & MS & $\mathrm{F}$ & $p$ & SD \\
\hline$\overline{\text { Total }}$ & 20 & $1.12 \times 10^{6}$ & 56003 & & & \\
\hline Constant & 1 & 920467 & 920467 & & & \\
\hline Total (Corrected) & 19 & 199593 & 10504.9 & & & 102.493 \\
\hline Regression & 5 & 185766 & 37153.2 & 37.6185 & 0 & 192.752 \\
\hline Residual & 14 & 13826.8 & 987.63 & & & 31.4266 \\
\hline Lack of Fit (model error) & 6 & 8443.66 & 1407.28 & 2.09138 & 0.165 & 37.5137 \\
\hline Pure Error (replicate error) & 8 & 5383.16 & 672.895 & & & 25.9402 \\
\hline $\mathbf{N}=20$ & $Q^{2}=0.869$ & & Cond. no. $=3.922$ & & & \\
\hline \multirow[t]{2}{*}{$\mathrm{DF}=14$} & $R^{2}=0.931$ & & Y-miss $=0$ & & & \\
\hline & $\mathrm{R}^{2}$ Adj. $=0.906$ & & $\mathrm{RSD}=31.4266$ & & & \\
\hline \multicolumn{7}{|l|}{$\mathrm{K}_{\mathrm{L}} \mathrm{a}$} \\
\hline Total & 20 & 55583.6 & 2779.18 & & & \\
\hline Constant & 1 & 49658.6 & 49658.6 & & & \\
\hline Total (Corrected) & 19 & 5925.00 & 311.842 & & & 17.659 \\
\hline Regression & 5 & 5754.58 & 1150.92 & 94.5509 & 0 & 33.9252 \\
\hline Residual & 14 & 170.414 & 12.1724 & & & 3.4889 \\
\hline Lack of Fit (model error) & 6 & 11.981 & 18.4969 & 2.48978 & 0.116 & 4.3008 \\
\hline Pure Error (replicate error) & 8 & 59.4329 & 7.42911 & & & 2.72564 \\
\hline $\mathbf{N}=20$ & $Q^{2}=0.947$ & & Cond. no. $=3.922$ & & & \\
\hline \multirow[t]{2}{*}{$D F=14$} & $R^{2}=0.971$ & & $Y$-miss $=0$ & & & \\
\hline & $R^{2}$ Adj. $=0.961$ & & $\mathrm{RSD}=3.4889$ & & & \\
\hline
\end{tabular}

Legend DF, degree of freedom; SS, sum of squares; MS, Mean Square (SS/DS); F, F-distribution value; $p$, probability; SD, standard deviation

that the statistical model can explain $93.1 \%$ of response variability. Also $\mathrm{Q}^{2}$, indicating the fraction of response variation that can be predicted by the model, was rather good (0.870). Finally, the rather high F-value (37.6) indicated that the model terms were quite significant.

For $\mathrm{K}_{\mathrm{L}} \mathrm{a}$, statistical parameters were even better being $\mathrm{R}^{2}$ 0.971, $\mathrm{Q}^{2} 0.947$ and F-value 99.6, respectively.

\section{Effects of aeration and agitation on $\mathrm{K}_{\mathrm{L}} \mathrm{a}$ and enzyme production}

Oxygen must be supplied to all aerobic cultures to satisfy the request for growth and production. In CSTRs this is mainly obtained by correct set up of aeration and agitation leading to the transfer of a sufficient oxygen amount to each cell. $\mathrm{K}_{\mathrm{L}} \mathrm{a}$ is the most significant parameter to measure transfer phenomena, including oxygen transfer, inside a bioreactor. $\mathrm{K}_{\mathrm{L}}$ a could be improved by increasing aeration and/or agitation but with technical and physiological (shear stress) limitations.

Figure 1 shows $\mathrm{K}_{\mathrm{L}}$ a values measured at various combinations of stirrer speed and aeration rate as suggested by the model.

The increase of both parameters, in all cases, led to increased $\mathrm{K}_{\mathrm{L}} \mathrm{a}$. However, considering the single parameter effect, agitation was much more effective than aeration, being its relative curve much more steep (Figure 1a).

This was even more evident considering the combined effect plotted in the response surface (Figure 1b). At 200 $\mathrm{rpm}, \mathrm{K}_{\mathrm{L}} \mathrm{a}$ increase was limited for every aeration rates. The stirrer was barely able to load the air flow ("loading") with consequent little air dispersion. Evident "flooding" (unperturbed air passage through the stirrer) was recorded in particular at highest flow rates. $\mathrm{K}_{\mathrm{L}}$ a measured at lowest aeration and highest agitation was much higher $\left(\right.$ ca. $\left.54 \mathrm{~h}^{-1}\right)$ than that in opposite conditions $\left(\mathrm{ca} .30 \mathrm{~h}^{-1}\right)$. It is worth noting that $\mathrm{K}_{\mathrm{L}} \mathrm{a}$ increasing rate (curve slope) at the highest values of both parameters was lower than that recorded at the lowest values. In fact, the response surface in the lower part of the plot (blue - dark green coded colours) was quite steep, while in the intermediate part (light green - orange colours) it started to flatten reaching almost a plateau thereafter (red zone). This could be due to possible saturation effect.

As expected, both aeration and agitation heavily influenced $L$. muscarium chitinolytic activity. However, unlike that occurred for $\mathrm{K}_{\mathrm{L}} \mathrm{a}$, positive effects were observed till a threshold level only, after which negative effects started. This was evident either when the factors where considered alone or in combination (Figure 2).

Figure 2a shows the single effect of aeration and agitation including maximum, minimum and average predicted activities (confidence level, 95\%). The predicted combined effects of the variables, given by a response surface plot, are shown in Figure 2b, while comparison between experimental and predicted data is reported in Table 2. 

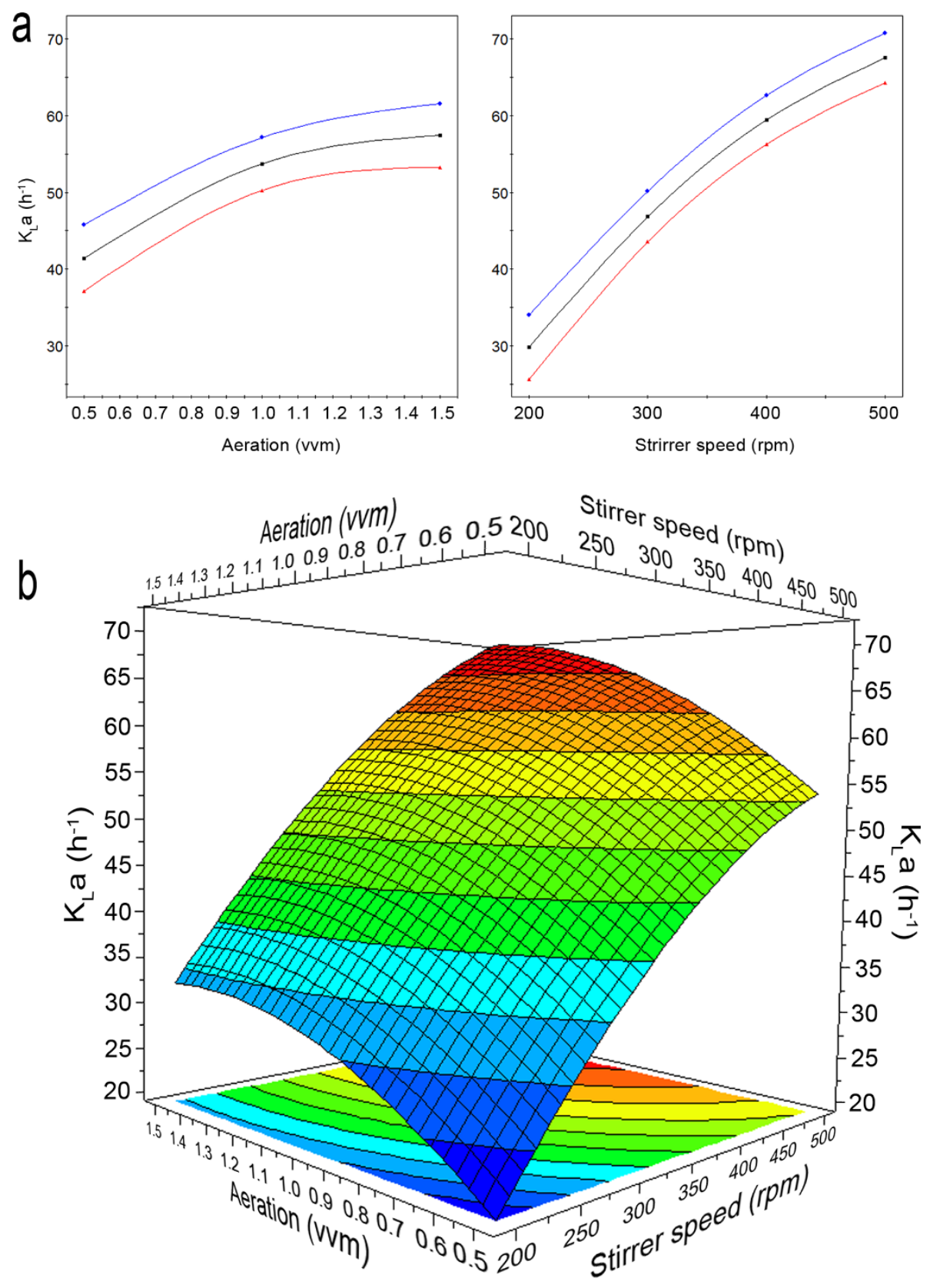

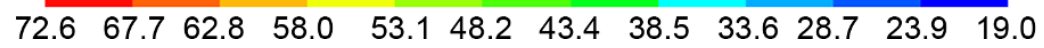

Figure 1 Single (a) and combined (b) effect of agitation and aeration on $\mathrm{K}_{\mathrm{L}}$ a measured in $2 \mathrm{~L}$ CSTR as predicted by RSM. (a) Prediction plot: average, minimum and maximum predicted values (confidence level, 95\%) were represented by the black, red and blue lines, respectively. (b) Surface response: color codes indicated different ranges of values.

Lowest activity (ca. $92 \mathrm{U} / \mathrm{L}$ ) was obtained at $0.5 \mathrm{vvm}$ both at 200 (T1, T15) and $500 \mathrm{rpm}$ (T11). Highest enzyme activity was achieved at $1.0 \mathrm{vvm}$ and $300 \mathrm{rpm}$ (T7, T19 and T20 average $=383.7 \pm 7.8 \mathrm{U} / \mathrm{L}$ ). In these conditions the predicted value was $360.47 \mathrm{U} / \mathrm{L}$ (Table 2). The optimal combination to obtain highest activity
(373.0 U/L), as predicted by the model, was $1.1 \mathrm{vvm}$ and $327 \mathrm{rpm}$ (Figure $2 \mathrm{~b}$ ). This condition was not included in the experimental design and additional experiments, carried out accordingly, confirmed model reliability. Actually, the production of chitinolytic enzymes $(378.3 \pm 6.1$ $\mathrm{U} / \mathrm{L}$ ) was not statistically different from the model 

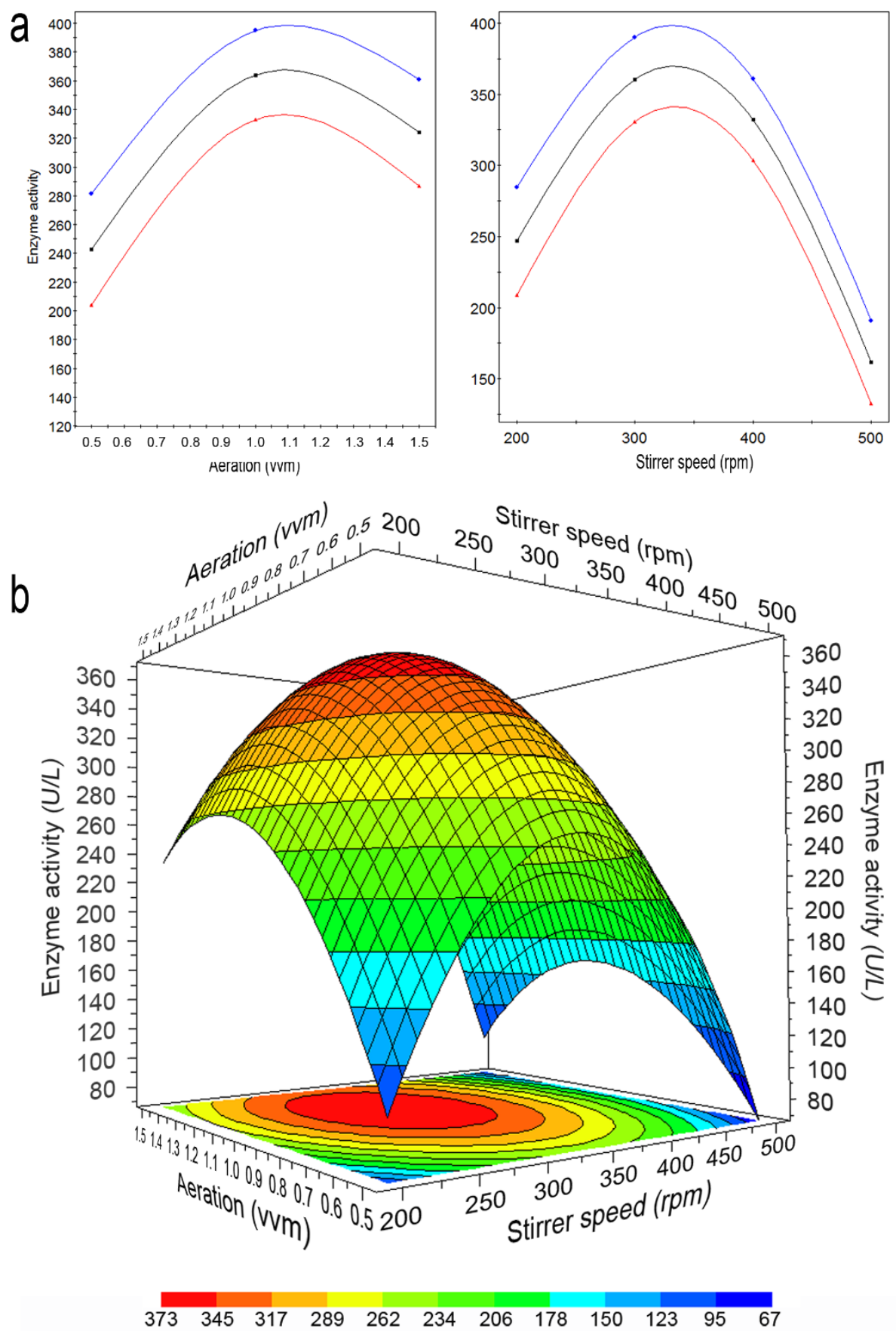

Figure 2 Single (a) and combined (b) effect of agitation and aeration on the total chitinolytic activity of L. muscarium CCFEE 5003 cultivated in $\mathbf{2}$ L CSTR as predicted by RSM. (a) Prediction plot: average, minimum and maximum predicted values (confidence level, 95\%) were represented by the black, red and blue lines, respectively. (b) Surface response: color codes indicated different ranges of values.

prediction. No statistical difference was found also with the value measured at $1.0 \mathrm{vvm}$ and $300 \mathrm{rpm}(383.7 \pm$ $7.8 \mathrm{U} / \mathrm{L}$ ) as mentioned before (Table 2).

Accordingly to the model, enzyme activity increased up to $1.1 \mathrm{vvm}$ and to $327 \mathrm{rpm}$; beyond these values, and regardless the combination chosen, it always decreased.
In certain conditions decrease was dramatic (i.e. agitation $>400 \mathrm{rpm}$ ). It is worth noting that, exceeding these threshold values, the negative effect of agitation was much higher than that of aeration. This is particularly evident observing the slopes of the plots showed in Figure 2a. 
Table 2 Experimental results and predicted data by the model

\begin{tabular}{ccc}
\hline Experiment (Thesis number) & Observed (U/L) & Predicted (U/L) \\
\hline T1 & 92.29 & 98.89 \\
T2 & 217.37 & 233.13 \\
T3 & 221.17 & 233.13 \\
T4 & 259.26 & 246.80 \\
T5 & 218.53 & 230.21 \\
T6 & 356.81 & 329.13 \\
T7 & 381.19 & 360.67 \\
T8 & 219.37 & 219.53 \\
T9 & 247.48 & 283.13 \\
T10 & 282.22 & 332.13 \\
T11 & 92.01 & 66.85 \\
T12 & 116.00 & 95.12 \\
T13 & 109.95 & 95.13 \\
T14 & 126.94 & 161.78 \\
T15 & 92.17 & 98.89 \\
T16 & 129.80 & 161.78 \\
T17 & 142.98 & 161.78 \\
T18 & 215.13 & 161.78 \\
T19 & 375.69 & 360.47 \\
T20 & 394.25 & 360.47 \\
\hline
\end{tabular}

These outcomes could be explained by several causes with possible synergisms. At low aeration and agitation, no sufficient oxygen was probably available for the fungal growth and consequent enzyme production. This was confirmed by the low $\mathrm{K}_{\mathrm{L}}$ a (Figure 1) and by the delay necessary to obtain the maximum activity (144 h instead of $72 \mathrm{~h}$, data not shown).

Lack of oxygen availability did not explain the low activities recorded beyond the mentioned values in correspondence of which $\mathrm{K}_{\mathrm{L}}$ a was always high. In these cases, shear stress could be the principal cause of cell sufferance and consequent low enzyme production. In addition, the enzyme, already released in the cultural broth, could be partially inactivated by the shear forces. Negative effects of stirring were never demonstrated for chitinolytic enzymes but they are known for other secreted proteins and could be related to catalytic dysfunctions due to conformational changes carried out by mechanical forces [24-27].

The negative effect of the increased stirrer speed was so strong to be higher than that caused by low oxygen availability. In fact, lowest enzyme activity (ca. $92 \mathrm{U} / \mathrm{L}$ ) was obtained both at $0.5 \mathrm{vvm}$ and $200 \mathrm{rpm}$, leading to lowest $\mathrm{K}_{\mathrm{L}} \mathrm{a}\left(18.3 \mathrm{~h}^{-1}\right)$ and at $0.5 \mathrm{vvm}$ and $500 \mathrm{rpm}$ with rather high $K_{L} a\left(51 h^{-1}\right)$. This effect was well evidenced in the response surface plot (Figure $2 \mathrm{~b}$ ).

Due to the scarce specific literature available, comparison of our results with those of other scientists is difficult. Some of our results were in contrast with those reported by Liu et al. [15] carried out by the OVT method. These authors correlated the production improvement with the increase of stirring with no mention to possible shear stress at high rates. Probably, in that case, the range of stirring tested ( 75 to $225 \mathrm{rpm}$ in a $5 \mathrm{~L}$ bioreactor) was too narrow and highest value too low to consent observations of this phenomenon. By contrast, our work agrees with these authors to correlate reduction of enzyme activity with the increase of aeration [15].

Negative effects, on chitinolytic enzymes production, by mechanical stress due to increasing stirrer speed in CSTR, were also observed for T. harzianum $[14,16]$.

\section{Bioprocess under optimized conditions}

In view of process scale-up to the industrial level, the use of low aeration and agitation rates is preferable for energy saving. In this context, $1.0 \mathrm{vvm}$ and $300 \mathrm{rpm}$ were preferable than $1.1 \mathrm{vvm}$ and $327 \mathrm{rpm}$ with (ca. $10 \%$ less). Therefore, these have been considered as optimal conditions for the cultivation of L. muscarium in bioreactor and its production of chitinolytic enzymes. Detailed studies on bioprocess kinetics have been carried out accordingly.

Figure 3a shows the time course of total chitinolytic activity, fungal biomass, dissolved oxygen (DO), $\mathrm{pH}$ and NAG production by L. muscarium CCFEE 5003 grown for $144 \mathrm{~h}$ under optimised conditions. Enzyme activity $383.7 \pm 7.8 \mathrm{U} / \mathrm{L}$ peaked at $72 \mathrm{~h}$ to strongly decrease thereafter. Maximum biomass production was delayed $(120 \mathrm{~h})$ in relation to the enzyme activity. This was probably due to a late availability of nutrients produced by chitin hydrolysis as confirmed by the peak of NAG recorded at $96 \mathrm{~h}$. $\mathrm{pH}$ increased from the initial value (5.5) up to ca. 7.5.

Detailed information, on the production of enzymes with different activity on chitin, was not obtained from the DNSA assay, revealing total chitinolytic activity, but using the 4-MU substrates (S1-S4). The time course of these different typologies of chitinolytic activities is shown in Figure 3b.

The pattern of enzymes produced was variable during the process in relation to the development of chitin hydrolysis. The enzymes with possible "endo-" or "exo-" activity (revealed by S2, S3 and S4) peaked at 48 h; while those hydrolysing the chitobiose (revealed by S1) peaked at $96 \mathrm{~h}$. In the early stages of chitin hydrolysis, coarse polymers fragmentation was probably carried out by endo-type enzymes (i.e. the chitinases, E.C. 3.2.1.14) with the contribution of eso-type activities (i.e. the $N$ acetyl-hexosaminidases, E.C. 3.2.1.52). Later on, massive chitobiose and NAG production were obtained from oligomers and longer segments. The degradation of chitobiose requires presence of the chitobiase: this activity is 

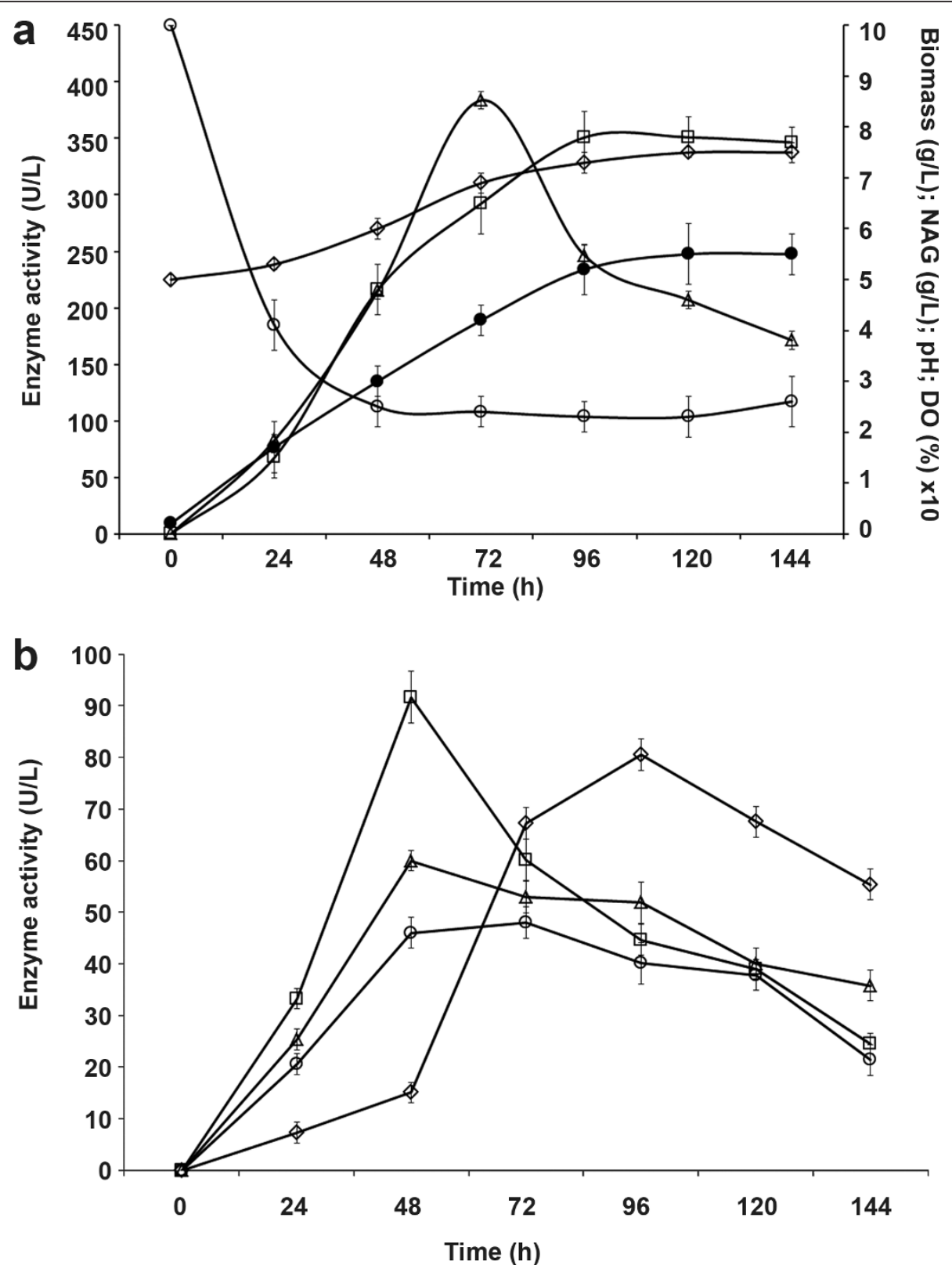

Figure 3 Time course of bioprocess parameters by L. muscarium CCFEE 5003 cultivated in 2 L CSTR under optimized conditions. (a)

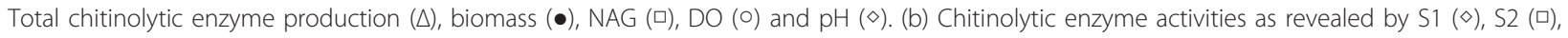
S3 $(\Delta)$ and S4 (o).

grouped by the Enzyme Commission within the $\mathrm{N}$ acetyl-hexosaminidases class.

The production of a complex and time-evolving pattern of chitinolytic enzymes by L. muscarium was confirmed when PAGE activity gels were obtained from fermentation broth samples taken at different times. These showed presence of various enzymes (at least 7) with different MWs (Figure 4). The first enzyme (MW of ca. $25 \mathrm{kDa}$ ) was revealed after $24 \mathrm{~h}$, increased thereafter and was constantly present along the whole process. By contrast, presence of other enzymes (MW from ca. 20 to ca. $55 \mathrm{kDa}$ ) was not constant. The production of a diversified large array of chitinolytic enzymes, showing complete competence in chitin hydrolysis, is typical of parasitic fungi such as Trichoderma species. By contrast, saprophytes often present few activities with limited competence on chitin degradation [3,28,29].

It is worth noting that, due to the establishment of much more suitable conditions, L. muscarium, when cultivated in bioreactor after the optimization reported 


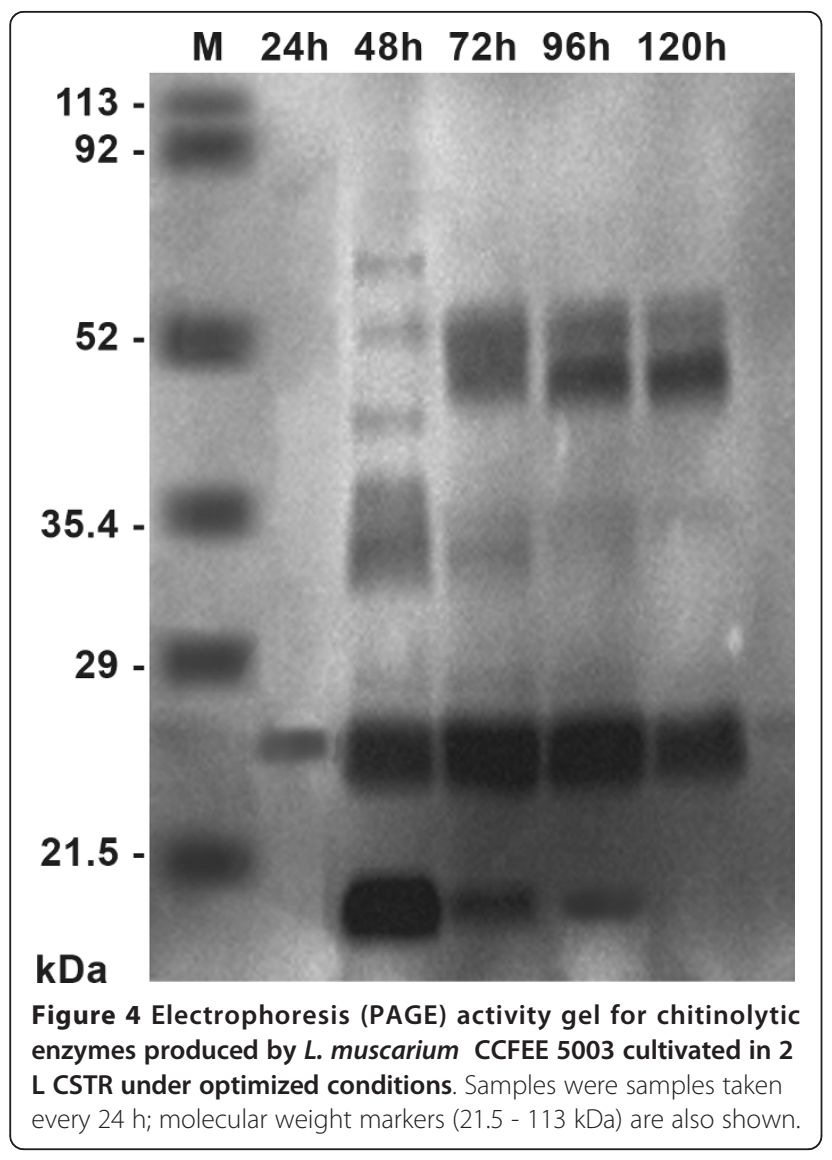

in this study, was able to release a number of chitinolytic enzymes higher than that obtained in shaken flasks as reported by Fenice and Gooday [3]. In addition, the total chitinolytic enzyme production increased by more than $25 \%$.

\section{Conclusions}

The Antarctic fungus L. muscarium CCFEE 5003 is a powerful chitinolytic organism never exploited at the industrial level. In this study we demonstrated its ability to growth and produce high levels of chitinolytic enzymes in CSTR. The optimization of the production process at laboratory level, carried out with a modern and efficient approach (RSM), permitted to obtain appreciable qualitative (increased number of enzymes) and quantitative (increased production) advantages. These are very important and promising assumptions in view of the development of an economically valuable industrial production.

\section{Material and methods Chemicals}

Chitin (from crab shells), $N$-acetyl-D-glucosamine (NAG), $N-N^{p}$ diacetylchitobiose and $N-N^{p}-N^{\prime \prime}$ triacetylchitotriose, cellobiose, 4 methylumbelliferone (4MU); 4- methylumbelliferyl $\mathrm{N}$-acetylglucosaminide (S1); 4-methylumbelliferyl $\beta$-D- $N, N^{\prime}$-diacetylchitobioside (S2); 4 methylumbelliferyl $N, N$, $N$ "-triacetylchitotrioside (S3) and 4-methylumbelliferyl $N, N, N$ ", $N^{\prime \prime \prime}$-tetraacetylchitotetraoside (S4) were from Sigma Chemicals (St. Louis, MO, USA); Malt Extract Agar (MEA) was from Oxoid (U.K.); Yeast Nitrogen Base (YNB) was from Difco (Detroit, MI, USA). All other chemicals were of analytical grade.

Colloidal chitin was prepared as already reported [30]. After swelling, chitin was re-suspended in water and autoclaved $\left(121^{\circ} \mathrm{C}, 20 \mathrm{~min}\right)$. Glycol chitin was prepared as reported by Molano et al. [31].

\section{Microorganism and inoculum preparation}

Lecanicillium muscarium Petch strain CCFEE 5003 (ex Verticillium lecanii Zimm strain A3), a fungus previously isolated from Antarctic moss [32], was stocked in the Culture Collection of Fungi from Extreme Environments (CCFEE:) of the Dipartimento di Scienze Ecologiche e Biologiche, University of Tuscia, Viterbo, Italy. During the study the strain was maintained and routinely sub-cultured on MEA slants. Inocula were produced as previously described [3].

\section{Bioreactor and fermentation conditions}

The bioreactor used was 2-1 (total volume) bench-top stirred tank reactor (STR) (Applikon Dependable Instruments, Schiedam, NL) filled with 1.21 of medium. The fermentor was equipped with a top stirrer bearing two six-blade Rushton-type turbines (diameter $4.5 \mathrm{~cm}$, blade width $1.4 \mathrm{~cm}$, blade length $1.4 \mathrm{~cm}$ ) and 2 baffles (width $1.4 \mathrm{~cm}$ ). Air was injected through a perforated pipe sparger located under the bottom turbine. The following probes were installed on the top plate: dissolved oxygen sensor (Ingold, $\mathrm{CH}$ ), double reference $\mathrm{pH}$ sensor (pHoenix Electrode Company, Houston, Texas, USA), PT 100 temperature sensor. Standard bioprocess conditions were as follows: inoculum size $0.5 \times 10^{6}$ conidia $/ \mathrm{ml}$; temperature $25^{\circ} \mathrm{C}$; initial dissolved oxygen $100 \%$ of saturation non-controlled; initial pH 5.0 non-controlled; basal fermentation medium (BM), as already reported as optimal for the chitinolytic enzyme production by the fungus [8], was: YNB 1\%, colloidal chitin 1\%. Silicone antifoam $0,2 \%$ was added to BM. Stirrer speed and aeration were set as reported below. All media were sterilized in the bioreactor for $30 \mathrm{~min}$ at $121^{\circ} \mathrm{C}$.

The fermentation parameters (temperature, $\mathrm{pH}$ and dissolved oxygen) were monitored by an adaptative/PID digital controller, ADI 1030 (Applikon Dependable Instruments, Schiedam, The Netherlands).

Samples were taken every $24 \mathrm{~h}$ and, after centrifugation $(10,000 \mathrm{~g}$ for $10 \mathrm{~min})$, supernatants used as enzyme solutions for the enzyme assay determination. 
Influence of the agitation on the mycelial growth and enzyme productions was evaluated at 200, 300, 400 and $500 \mathrm{rpm}$ (corresponding to tip speed of 47.12, 70.68, 94.28 and $117.81 \mathrm{~cm} / \mathrm{s}$, respectively); the effect of aeration was tested at $0.5,1.0$ and $1.5 \mathrm{vvm}$. Both these parameters were optimised by RSM.

\section{Measure of $\mathrm{K}_{\mathrm{L}} \mathrm{a}$}

The volumetric mass-transfer coefficient $\left(\mathrm{K}_{\mathrm{L}} \mathrm{a}\right)$ of the bioreactors was determined by the static method of gassing out of Wise [33] using BM at different combinations of aeration rates $(0.5,1.0$ and $1.5 \mathrm{vvm})$ and stirrer speeds (200, 300, 400 and $500 \mathrm{rpm}$ ) as suggested by the model. Tests were carried out at $25^{\circ} \mathrm{C}$.

\section{Analytical methods}

For the RSM the overall chitinolytic activity was determined by the method of dinitrosalicylic acid (DNSA), using $\mathrm{N}$-Acetyl-D-glucosamine for standard curve, as previously reported [8]. For the production of chitinolytic enzymes under optimised condition activities were detected also by the release of 4 methylumbelliferone from 4MU substrates, using 4 methylumbelliferone for the standard curve, as reported by McCreath and Gooday [34].

Under the assay conditions, one unit (U) of enzyme activity was defined as the amount of enzyme which released $1 \mu \mathrm{mol}$ per ml per min.

The mycelial growth was measured as reported by Fenice et al. [8].

\section{Electrophoresis and activity gels}

Presence of various chitinolytic enzymes and their molecular weight $(\mathrm{MW})$ was also determined using onedimensional activity polyacrylamide gel electrophoresis (PAGE) following the procedure of Trudel and Asselin [35].

Markers (range 15-150 kDa) were from Bio-rad Laboratories (Ca, USA).

\section{Experimental factorial design by RSM}

Effect of the combined action of aeration and agitation on the production of chitinolytic activity and $\mathrm{K}_{\mathrm{L}} \mathrm{a}$ (response variables) was optimised by a D-optimal design, with the following independent variables (factors)

$$
\begin{aligned}
& \mathrm{X}_{1}=\text { Aeration (vvm of air) } \\
& X_{2}=\text { Agitation (rpm) }
\end{aligned}
$$

The above dimensional independent variables were coded as dimensionless terms by the following equation:

$$
\mathrm{X}_{i}=\left(\mathrm{A}_{i}-\mathrm{A}_{0}\right) / \Delta \mathrm{A} \quad \mathrm{i}=1,2
$$

Table 3 Experimental setup combining aeration and agitation as suggested by the model

\begin{tabular}{cll}
\hline $\begin{array}{c}\text { Experiment } \\
\text { (Thesis number) }\end{array}$ & Aeration (vvm) & Stirrer speed (rpm) \\
\hline T1; T15 & 0.5 & 200 \\
T2; T3 & 1.5 & 200 \\
T4 & 1.0 & 200 \\
T5 & 0.5 & 300 \\
T6 & 1.5 & 300 \\
T7; T19; T20 & 1.0 & 300 \\
T8 & 0.5 & 400 \\
T9 & 1.5 & 400 \\
T10 & 1.0 & 400 \\
T11 & 0.5 & 500 \\
T12; T13 & 1.5 & 500 \\
T14; T16; T17; 118 & 1.0 & 500 \\
\hline
\end{tabular}

where $\mathrm{X}_{i}$ is a coded value and $\mathrm{A}_{i}$ is the actual value of the variable, $\mathrm{A}_{o}$ is the actual value of the same variable at the centre point and $\Delta \mathrm{A}$ is the variable step change.

The range of the variables is given in Table 3 .

Data were subjected to analysis of variance (ANOVA) and fitted according to a second-order polynomial model shown by:

$$
Y=\beta o+\sum \beta_{\mathrm{i}} X_{\mathrm{i}}+\sum \beta_{\mathrm{ii}} X_{\mathrm{i}}^{2}+\sum \beta_{\mathrm{ij}} X_{\mathrm{i}} X_{\mathrm{j}}
$$

where $Y$ is the predicted response variable, $\beta$ o is the intercept, $\beta \mathrm{i}$ and $\beta \mathrm{ii}$ linear coefficient and quadratic coefficient, respectively, $\beta \mathrm{ij}$ is the interaction coefficient and $X \mathrm{i}$ and $X \mathrm{j}$ are the coded forms of the input variables. To estimate the impact of single independent variables on the response, regardless of the presence of the other factors, main effects were calculated using:

$$
Y=\beta o+\beta_{\mathrm{i}} X_{\mathrm{i}}+\beta_{\mathrm{ii}} X_{\mathrm{i}}^{2}
$$

Statistical examination of results and response surface study were carried out by the MODDE 5.0 software (Umetrics AB, Sweden).

Fermentations under optimal conditions for best enzyme production, as suggested by the model, were carried out in triplicate in subsequent experiments.

\section{Acknowledgements}

This work was partially supported by the Italian National Program for Antarctic Researches (PNRA: Programma Nazionale Ricerche Antartiche).

\section{Authors' contributions}

MF and PB carried out the design of this study. MF overviewed fermentations, performed determinations and data analysis. LS was responsible of fermentations and performed determinations. PB performed data analysis. MF, PB, LS and FF participated in writing and critical manuscript review. All authors have read and approved the manuscript.

\section{Competing interests}

The authors declare that they have no competing interests. 
Received: 6 December 2011 Accepted: 23 January 2012

Published: 23 January 2012

\section{References}

1. De la Cruz J, Rey M, Lora JM, Hidalgo-Gallego A, Dominiguez F, PintorToro JA, Llobell A, Benitez T: Carbon source control on $\beta$-glucanases, chitobiase and chitinase from Trichoderma harzianum. Arch Microbiol 1993, 159:316-322

2. Muzzarelli RAA: Advanced in N-acetyl-glucosaminidases. In Chitin Enzymology. Volume 1. Edited by: Muzzarelli RAA. Grottammare, Italy. Atec Edizioni; 1993:357-373.

3. Fenice M, Gooday GW: Mycoparasitic actions against fungi and oomycetes by a strain (CCFEE 5003) of the fungus Lecanicillium muscarium isolated in Continental Antarctica. Ann Microbiol 2006, 56:1-6.

4. Juarez-Jimenez B, Rodelas B, Martinez-Toledo MV, Gonzalez-Lopez J, Crognale S, Gallo AM, Pesciaroli C, Fenice M: Production of chitinolytic enzymes by a strain (BM17) of Paenibacillus pabuli isolated from crab shells samples collected in the East Sector of Central Tyrrhenian Sea. Int J Biol Macr 2008, 43:27-31.

5. Fenice M, Di Giambattista R, Leuba JL, Federici F: Inactivation of Mucor plumbeus by the combined action of chitinase and high hydrostatic pressure. Int J Food Microbiol 1999, 52:109-113.

6. Esti M, Ceccantoni B, Fenice M: Inhibition of the ochratoxin-A producer Aspergillus carbonarius by fungal chitinase application on grape. Book of abstracts of the International Workshop on the Advanced in Grapevine and Wine Research Venosa, Italy. Ed V. Nuzzo; 2005, 50.

7. Aloise PA, Lumme M, Haynes CA: N-acetyl-D-glucosamine production from chitin-waste using chitinases from Serratia marcescens. In Chitin Enzymology. Volume 2. Edited by: Muzzarelli RAA. Grottammare, Italy. Atec Edizioni; 1996:581-594.

8. Fenice M, Selbmann L, Di Giambattista R, Petruccioli M, Federici F: Production of extracellular chitinolytic activities by a strain of the antarctic entomogenous fungus Verticillium cfr. lecanii. In Chitin Enzymology. Volume 2. Edited by: Muzzarelli RAA. Grottammare, Italy. Atec Edizioni; 1996:285-292.

9. Fenice M, Selbmann L, Zucconi L, Onofri S: Production of extracellular enzymes by Antarctic fungal strains. Polar Biol 1997, 17:275-280.

10. Fenice M, Selbmann L, Di Gianbattista R, Federici F: Chitinolytic activity at low temperature of an antarctic strain (A3) of Verticillium cfr lecanii. Res Microbiol 1998, 149:289-300.

11. Malathrakis NE, Kritsotaki O: Effect of substrate, temperature and time of application on the effectiveness of three antagonistic fungi against Botrytis cinerea. Recent Advances in Botrytis Research Wageningen. Pudoc Scientific Publishers; 1992, 187-191.

12. Cerrone F, Barghini P, Pesciaroli C, Fenice M: Efficient removal of pollutants from olive washing wastewater in bubble-column bioreactor by Trametes versicolor. Chemosphere 2011, 84:254-259.

13. Bas D, Boyaci HI: Modeling and optimization II: Comparison of estimation capabilities of response surface methodology with artificial neural networks in a biochemical reaction. J Food Eng 2007, 78:846-854.

14. Felse PA, Panda T: Submerged culture production of chitinase by Trichoderma harzianum in stirred tank bioreactors - the influence of agitator speed. Biochem Eng J 2000, 4:115-120.

15. Liu BL, Kao PM, Tzeng YM, Feng C: Production of chitinase from Verticillium lecanii F091 using submerged fermentation. Enzyme Microb Tech 2003, 33:410-415.

16. Abd-Aziz S, Fernandez CC, Salleh MM, Illias RM, Hassan MA: Effect of Agitation and aeration rates on chitinase production using Trichoderma virens UKM1 in 2-I stirred tank reactor. Appl Biochem Biotechnol 2008, 150:193-204.

17. Marin-Cervantes MC, Matsumoto Y, Ramirez-Coutino L, Rocha-Pino Z, Viniegra G, Shirai K: Effect of moisture content in polyurethane foams as support for solid-substrate fermentation of Lecanicillium lecanii on the production profiles of chitinases. Process Biochem 2008, 43:24-32

18. Wasli AS, Salleh MM, Abd-Aziz S, Hassan O, Mahadi NM: Medium optimization for chitinase production from Trichoderma virens using central composite design. Biotechnol Bioproc Eng 2009, 14:781-787.

19. Fisher RA: In Statistical methods, experimental design, and scientific inference. Edited by: Bennet JH. Oxford University Press, Oxford; 1990:, (A re-issue of statistical methods for research workers (1925), the design of experiments (1935) and statistical methods and scientific inference (1956)).
20. Box GEP, Hunter JS, Hunter WG: Statistics for experimenters: design, innovation, and discovery. 2 edition. NY, USA: Wiley; 2005.

21. Montgomery DC: Design and analysis of experiments New York: Wiley; 2005.

22. Nawani NN, Kapadnis BP: Optimization of chitinase production using statistics based experimental designs. Process Biochem 2005, 40:651-660

23. Wang $Y$, Fang $X, A n F$, Wang $G$, Zhang $X$ : Improvement of antibiotic activity of Xenorhabdus bovienii by medium optimization using response surface methodology. Microb Cell Fact 2011, 10:98.

24. Scopes RK: Protein purification principles and practice Springer. USA; 1994

25. Amanullah A, Christensen LH, Hansen K, Nienow AW, Thomas CR: Dependence of morphology on agitation intensity in fed-batch cultures of Aspergillus oryzae and its implications for recombinant protein production. Biotechnol Bioeng 2002, 77:815-826.

26. D'Annibale A, Quaratino D, Federici F, Fenice M: Effect of agitation and aeration on the reduction of pollutant load of olive mill wastewater by the white rot fungus Panus tigrinus. Biochem Eng J 2006, 29:243-249.

27. Herpoel I, Asther M, Sigoillot JC: Design and scale-up of a process for manganese peroxidase production using the hypersecretory strain Phanerochaete chrysosporium 1-1512. Biotechnol Bioeng 1999, 65:468-473.

28. Chet I: Trichoderma-application, mode of action, and potential as biocontrol agent in soilborne plant pathogenic fungi. Innovative approaches to plant disease control Wiley \& Sons. New York; 1987, 137-160.

29. Di Giambattista R, Federici F, Petruccioli M, Fenice M: The chitinolytic activity of Penicillium janthinellum P9: purification, partial characterisation and potential applications. J App/ Microbiol 2001, 91:498-505.

30. Hankin L, Anagnostakis SL: The use of solid media for detection of enzyme production by fungi. Mycologia 1975, 67:597-607.

31. Molano J, Polachek I, Duran A, Cabib E: An endochitinase from 12 wheat germ: activity on nascent and preformed chitin. J Biol Chem 1979, 254(suppl 13):4901-4907.

32. Zucconi L, Pagano S, Fenice M, Selbmann L, Tosi S, Onofri S: Growth temperature preferences of fungal strains from Victoria Land, Antarctica. Polar Biol 1996, 16:53-61.

33. Wise WS: The measurement of the aeration of culture media. J Gen Microbiol 1951, 5:167-177.

34. McCreath KJ, Gooday GW: A rapid and sensitive microassay for determination of chitinolytic activity. J Microbiol Meth 1992, 14:229-237.

35. Trudel J, Asselin A: Detection of chitinase activity after polyacrylamide gel electrophoresis. Anal Biochem 1989, 178:362-366.

doi:10.1186/1475-2859-11-12

Cite this article as: Fenice et al:. Combined effects of agitation and aeration on the chitinolytic enzymes production by the Antarctic fungus Lecanicillium muscarium CCFEE 5003. Microbial Cell Factories 2012 11:12.

\section{Submit your next manuscript to BioMed Central and take full advantage of:}

- Convenient online submission

- Thorough peer review

- No space constraints or color figure charges

- Immediate publication on acceptance

- Inclusion in PubMed, CAS, Scopus and Google Scholar

- Research which is freely available for redistribution 